\title{
HOW DOES RESTORED HABITAT FOR CHINOOK SALMON (ONCORHYNCHUS TSHAWYTSCHA) IN THE MERCED RIVER IN CALIFORNIA COMPARE WITH OTHER CHINOOK STREAMS?
}

\author{
L. K. ALBERTSON ${ }^{\mathrm{a} *}$, L. E. KOENIG ${ }^{\mathrm{a}}$, B. L. LEWIS ${ }^{\mathrm{a}}$, S. C. ZEUG ${ }^{\mathrm{a}}$, L. R. HARRISON ${ }^{\mathrm{b}}$ AND B. J. CARDINALE ${ }^{\mathrm{a}, \mathrm{c}}$ \\ ${ }^{a}$ Department of Ecology, Evolution, and Marine Biology, University of California-Santa Barbara, Santa Barbara, California, USA \\ ${ }^{\mathrm{b}}$ Department of Earth Sciences, University of California-Santa Barbara, Santa Barbara, California, USA \\ ${ }^{\mathrm{c}}$ School of Natural Resources and Environment, University of Michigan, Ann Arbor, Michigan, USA
}

\begin{abstract}
The amount of time and money spent on restoring rivers for declining populations of salmon has grown substantially in recent decades. But despite the infusion of resources, many studies suggest that salmon populations are continuing to decline, leading some to question the effectiveness of restoration efforts. Here we examine whether a particular form of salmon restoration-channel reconfiguration with gravel augmentation-generates physical and biological habitat that is comparable with other streams that support salmon. We compared a suite of habitat features known to influence the various life stages of Chinook salmon in a restoration project in California's Merced River with 19 other streams that also support Chinook that we surveyed in the same geographic region. Our survey showed that riffle habitats in the restored site of the Merced River have flow discharge and depth, substrate and food web characteristics that cannot be distinguished from other streams that support Chinook, suggesting that these factors are unlikely to be bottlenecks to salmon recovery in the Merced. However, compared with other streams in the region, the Merced has minimal riparian cover, fewer undercut banks, less woody debris and higher water temperatures, suggesting that these factors might limit salmon recovery. After identifying aspects in the Merced that differ from other streams, we used principal components analysis to correlate salmon densities to independent axes of environmental variation measured during our survey. These analyses suggested that salmon densities tend to be greatest in streams that have more undercut banks and woody debris and lower water temperatures. These are the same environmental factors that appear to be missing from the Merced River restoration effort. Collectively, our results narrow the set of candidate factors that may limit salmon recovery in channel reconfiguration restoration efforts. Copyright (C) 2012 John Wiley \& Sons, Ltd.
\end{abstract}

Supporting information may be found in the online version of this paper.

KEY WORDS: restoration; gravel augmentation; channel reconstruction; regional reference; survey

Received 25 June 2011; Revised 26 August 2011; Accepted 21 September 2011

\section{INTRODUCTION}

River restoration has received increasing interest over the past several decades as natural habitats have become progressively degraded. These restoration efforts often vary in goal and scope but generally attempt to reconstruct river channels so that erosion and transport of fine sediments from agricultural land is reduced, in-stream habitat heterogeneity is enhanced, connection with the flood plain is increased and water quality is improved (Trush et al., 2000; Bernhardt et al., 2005). Despite a large increase in the number of restoration efforts, critics have shown that most projects lack clear goals for data collection, benchmarks that restoration sites should ultimately resemble (i.e. good reference conditions)

*Correspondence to: L. K. Albertson, Department of Ecology, Evolution, and Marine Biology, University of California-Santa Barbara, Santa Barbara, California 93106, USA.

E-mail: lindsey.albertson@lifesci.ucsb.edu and long-term monitoring (Jungwirth et al., 2002; Kondolf et al., 2007; Palmer, 2009). Additionally, the majority of salmon restoration projects do not provide pre-treatment sampling that would allow rigorous temporal comparisons that could be used to evaluate the restoration's success (Hicks et al., 1991). As such, a large fraction of studies that evaluate restoration efforts are forced to use post hoc spatial comparisons with a reference location, which can be a comparably weak form of inference because of the inherent problems of finding historically comparable sites (Jungwirth et al., 2002; Roni et al., 2005).

The lack of historical data and obvious reference sites is a common problem faced in California, which is one of the most active zones for restoration in the US (Bernhardt et al., 2005). Many restoration projects in California focus on restoring habitat required by threatened anadromous fish species like Chinook salmon (Oncorhynchus tshawytscha). Although Chinook in California once supported a vibrant 
fishery, populations have dwindled (Yoshiyama et al., 2001; Pacific Fisheries Management Council, 2008). There are a number of hypothesized causes for the decline in Chinook populations (Moyle, 1994), including loss of spawning and rearing habitat in rivers because of altered flow regimes from damming and agricultural diversions, gravel mining, introduced species and nutrient enrichment. In an attempt to improve degraded habitat, a large number of restoration projects in California have tried to reconfigure stream channels and/or enhance riverbeds with rocks of the ideal size and shape to encourage adult spawning (Kondolf and Mathews, 1993). During this processes, channels are restructured in ways that (i) enhance bed movement and the formation of heterogeneous riffle-pool sequences during high discharge events and (ii) enhance physical properties of the river bed that are thought to be important for Chinook spawning, such as the homogenization of substrate by removing both fine particulates that might harm eggs and juveniles (Chapman, 1988) and large boulders that might hinder construction of redds.

We recently began looking at how a case study of largescale river channel reconstruction in California's Merced River has altered physical and biological characteristics of the riverbed in ways that might impact Chinook (Albertson et al., 2010; Romanov et al., in revision; Utz et al., in review). Channel reconstruction of a $2.7-\mathrm{km}-$ long reach in the Merced River took place in 2001 following a levee failure that created a braided and frequently ponded area of the river that was not viewed as suitable habitat for salmon (California Department of Water Resources, 2001). After reconstruction (described more in the Methods), channel morphology and bed condition evolved through the accumulation of bed material from upstream sources during flood events (Legleiter et al., 2011), creating a sinuous river channel with developing bar-point geomorphology. Ideally, resources would have been allocated for pre-reconstruction and postreconstruction monitoring data so that the impacts of channel reconfiguration could be assessed with a before-after control impact analysis (Stewart-Oaten et al., 1986). But like most restoration efforts, no pre-restoration monitoring was performed, and post-monitoring was only given consideration well after the project was completed.

Given the data limitations, our initial approach to studying this system was to compare physical and biological characteristics of the Merced's restored site with those of an upstream 'reference' site that had not been restored. The rationale for this comparison was that the close proximity of the two locations ensured that physical conditions could be compared between reaches that, at the least, shared a common species pool and had similar underlying geology. Based on this upstream-downstream comparison, we showed that invertebrate communities in the restored site achieve lower abundance and biomass than those of the reference site and shift from sessile net-spinning hydropsychid caddisflies in the reference site to highly mobile grazing Baetis mayflies in the restored site (Albertson et al., 2010). Small-scale experiments suggest that these shifts are at least partly because of increased mobility and homogeneity of substrates in the restored site (Albertson et al., 2010). We also found that native Sacramento pikeminnow (Ptychocheilus grandis) are less abundant in the restored site but have faster growth rates (Romanov et al., in revision) and that juvenile Chinook salmon in the restored site specialize their feeding on Baetis mayflies and experience growth rates comparable fish in the unrestored reference (Utz et al., in review). Collectively, these studies suggest a rather dramatic shift in the invertebrate food web of the restored reach, probably driven by changes in geomorphology, which are influencing the diets, growth and possibly abundance of several resident fish species. However, a key limitation of using the upstream reach as a reference is that the reference location has itself experienced a variety of human-induced changes, including replacement of the riparian corridor with agriculture land, reduced flow because of dam control and water diversion, and sedimentation. So although we have been able to document that the restored section of the Merced River is different from an upstream stretch of river that was not influenced by the restoration effort, our studies do not indicate whether the restored section of the Merced has created habitat more capable of supporting Chinook.

Given the limitations of our upstream reference-downstream restored comparison and extensive literature suggesting that a regional perspective may help better define effective goals, management strategies and restoration techniques (Poff and Ward, 1990; Brinson and Rheinhardt, 1996; Ziemer, 1997; Liermann and Roni, 2008), we initiated a complementary study that aimed to compare the physical and biological characteristics of the restored Merced River with a broader array of streams in California's Central valley that are known to support Chinook populations. To do this, we conducted a regional survey of biological and physical factors that are thought to influence various life stages of Chinook (eggs, juveniles and spawning adults) in 20 streams throughout California's Central Valley where biologists from the Department of Fish and Game have monitored spawning populations of adult Chinook. We used data from our regional comparisons to ask two complementary questions. First, which characteristics of the restored section of the Merced River are different from conditions of 19 other streams in the region that support salmon? Addressing this question is an important first step in identifying which factors might be bottlenecks that limit recovery of salmon populations in the Merced. We then used our data to ask which habitat characteristics measured in all streams of the data set correlate most strongly with documented salmon densities throughout the Central Valley of California. Although correlation does not imply causation, this second analysis is potentially useful because it helps identify factors that do not correlate with regional 
differences in salmon density among streams. Uncorrelated factors are less likely to limit salmon recovery than factors that both (i) correlate with regional salmon densities and (ii) are missing from the Merced River. As we will show, these approaches converge on a set of common hypotheses that may help explain which factors limit the recovery of salmon populations in the Merced River and perhaps in similar restoration efforts as well.

\section{METHODS}

\section{Regional comparisons for the Merced}

Merced channel reconstruction. Restoration of the 'Robinson reach' in the Merced River (lat $37^{\circ} 29^{\prime} \mathrm{N}$, long $120^{\circ} 28^{\prime} \mathrm{W}$ ) occurred in 2001 as part of the Merced River Salmon Habitat Enhancement Project. Flows in the Merced are reservoir dominated, and regulated by the New Exchequer Dam, flood pulses typically occur biannually in April and November, and bank-full flow capacity of the channel is approximately $48.14 \mathrm{~m}^{3} \mathrm{~s}^{-1}$ (California Department of Water Resources, 2001). Prior to restoration, a flood in 1997 resulted in levee failure that redirected all flow to an area formerly mined for gravel, which created a $2.7 \mathrm{~km}$ braided section of stream that was broad, shallow and occasionally ponded (California Department of Water Resources, 2001). During reconstruction, the stream channel and floodplain in this area were re-graded and re-surfaced to produce a meandering, single-thread channel that contained alternating riffles and pools with a gravel bed of median rock size $55 \mathrm{~mm}$ in diameter. Channel width (approximately $30 \mathrm{~m}$ ), gradient, sinuosity and bed texture were designed so that the river flow would generate bed-material transport to maintain riffles that are not clogged with fine sediment and which would be gradually reshaped into pointbars. These habitat characteristics were established with the goal of recreating the natural meandering state of the river with habitat where adult Chinook are hypothesized to have spawned before the levee failure (California Department of Water Resources, 2001). We began our studies here using a nearby upstream reference site in an attempt to evaluate whether these goals were met.

Regional site selection. To expand our reference condition, we compared habitat characteristics in the restored Merced River with other streams in the same geographic region that are known to support salmon in California's Central Valley. We first identified all streams in the Central Valley that currently support viable populations of Chinook. To do this, we used published information from the California Department of Fish and Game (CDFG)'s Central Valley Salmon and Steelhead Monitoring Programs (Table I; Low, 2007) and the National Oceanic and Atmospheric Administration (NOAA) Chinook Salmon Current Stream Habitat Distribution Table (http://swr. nmfs.noaa.gov/hcd/dist2.htm). We considered any streams that were listed in these references as having annual runs or confirmed intermittent runs as streams that could presently support salmon. After streams that could support salmon were identified, sampling locations were selected within each stream based on CDFG-designated spawning areas, which were summarized in NOAA's Central Valley Chinook Salmon Current Stream Habitat Distribution Table. During this process, we reduced the total number of streams that could support salmon to a subset of 19 streams that could be accessed by wading. After identifying sampling locations in accessible streams, we travelled to each stream to sample habitat characteristics in two riffles per stream located within the most upstream designated spawning zone that was also accessible by vehicle or foot. In three cases (Dye Creek, Stanislaus River, Toomes Creek), only one riffle could be located and sampled. We fully recognize the limitations of sampling only two riffles within each stream, as two riffles cannot possibly characterize the entire spawning area for a given stream. Thus, the primary risk of this sampling design is that we do not accurately capture the mean value of any given variable for any particular stream (Hughes and Peck, 2008). Nevertheless, we consciously chose to put our limited time into sampling a great number of streams in lieu of intensive characterization of a small number of streams. We chose this design because it maximizes variation among the measured variables that is, as has been advocated by statisticians, a far more powerful approach for identifying outliers, and for ordination of measured variables (Cottingham et al., 2005). So long as the relative variation among streams is maintained, the lack of accurate characterization within any single stream has no bearing on statistical inferences.

Field sampling and overview of measured variables. In each stream, we sampled approximately 15 habitat characteristics that are thought to influence the survivorship of salmon eggs, fitness of juveniles, or habitat choice and spawning by adult salmon (see Table II for a summary; Groot and Margolis, 1991; Barbour et al., 1999). Sampling took place between 20 June and 4 July 2008. This time frame corresponds to a period of summer base flows in the Central Valley of California, and it follows the annual spring migration of juvenile Chinook. It might have been preferable to complete all of our sampling in the fall or spring when adults, eggs or juveniles are actually present in the stream channels. However, the CDFG constrains permits during the spawning and rearing periods such that the summer months immediately following migration represents the first time that streams are accessible. We should note, however, that the timing of sampling does place certain constraints on our interpretation of data because it was not possible to measure habitat characteristics when fish were actually present in the stream. For most variables (e.g. 
Table I. For each of 20 streams in California's Central Valley where we surveyed habitat in 2008, the matrix shows the method used by the California Department of Fish and Game to estimate Chinook population size in past years. Methods were obtained from Low, 2007 or from CDFG personal communication.

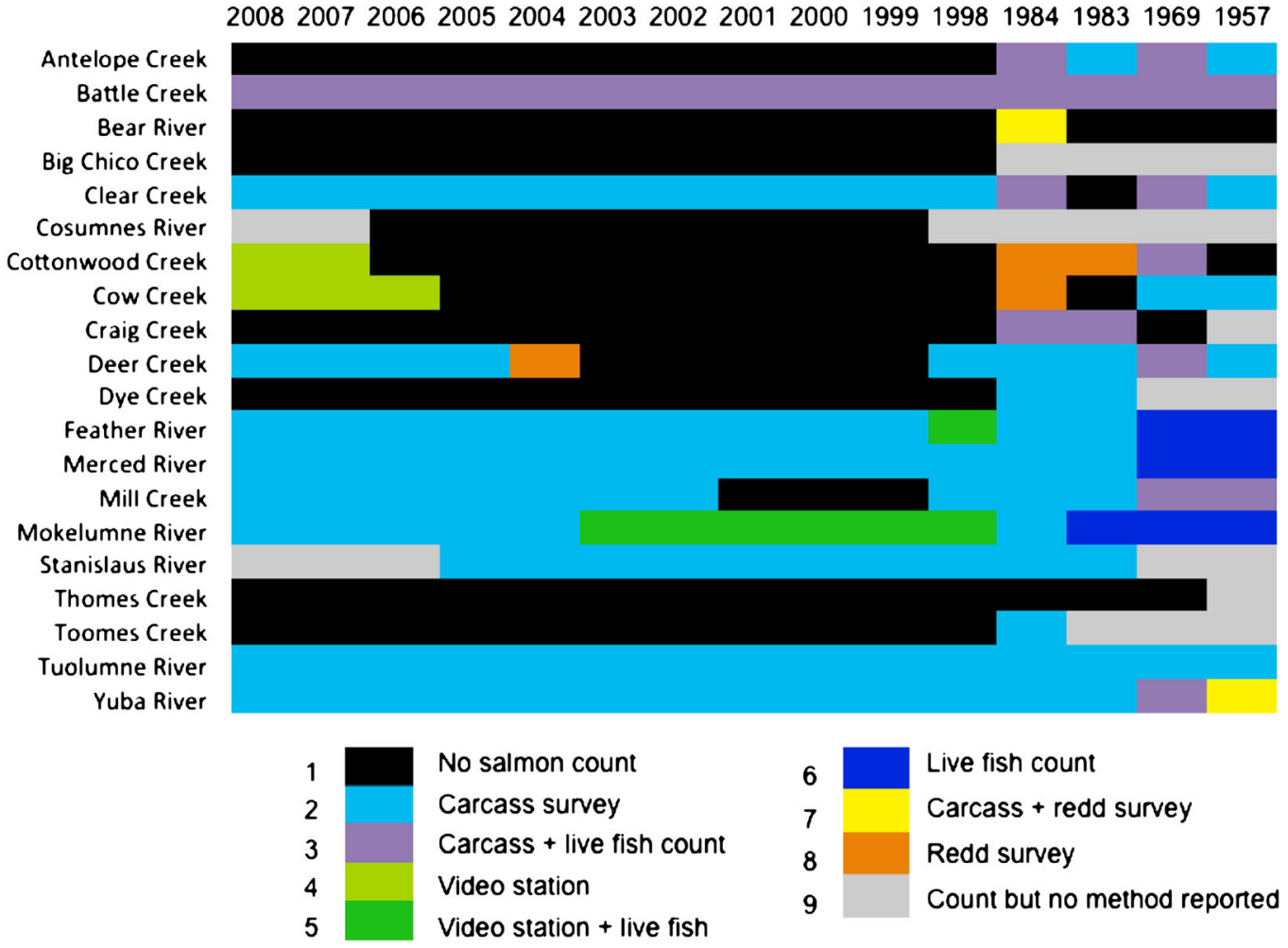

A total of nine methods have been described and the method used for any given population size estimate varies between rivers and between years on the same river.

riverbed grain size), this mismatch between the periods of biological activity and period of sampling is likely to be small and seems unlikely to show much change between months. But for select variables, of which water temperature is the most obvious and problematic, there is potential for large seasonal fluctuations. To deal with this potential mismatch, we examined whether variation in temperature among streams for the period in which we sampled was representative of the differences in water temperature for those same streams during the spring when juvenile fish are present. To do so, we correlated our summer temperature measurements to daily average temperature measurements taken from 1 April to 31 May 2008 in a subset of the streams that we surveyed where gauges maintained by the California Department of Water Resources record temperature throughout the year. The Pearson correlation between spring and summer temperature measurements was positive and strong $(r=0.75, p=0.05)$ (Figure S1). This indicates that although the absolute summer temperatures differ from spring values, the relative differences in stream water temperature are preserved. In other words, streams that are relatively cold in the spring are also colder in summer, and streams that are relatively warm in the spring are also relatively warm in the summer.

Flow and geomorphology. We measured several factors that characterize flow and geomorphology in riffles where Chinook spawn. Chinook can spawn in as little as $5 \mathrm{~cm}$ of water and as much as several metres of water if the velocity is not too fast (Groot and Margolis, 1991). To characterize both the mean water depth and velocity at our sampling locations, we measured 20 evenly spaced locations along the wetted width using a Sontek FlowTracker Velocimeter attached to a wading rod calibrated so that velocity readings were taken at $60 \%$ of the channel depth. Mean annual discharge data, another variable known to influence spawning and juvenile migration timing, were collected from the closest gauge station maintained by either the United States Geological Survey (USGS) or the California Department of Water Resources. Water temperature $\left({ }^{\circ} \mathrm{C}\right)$ was measured at midchannel using an YSI 85 probe (YSI Incorporated, Yellow Springs, OH, USA). Chinook also 


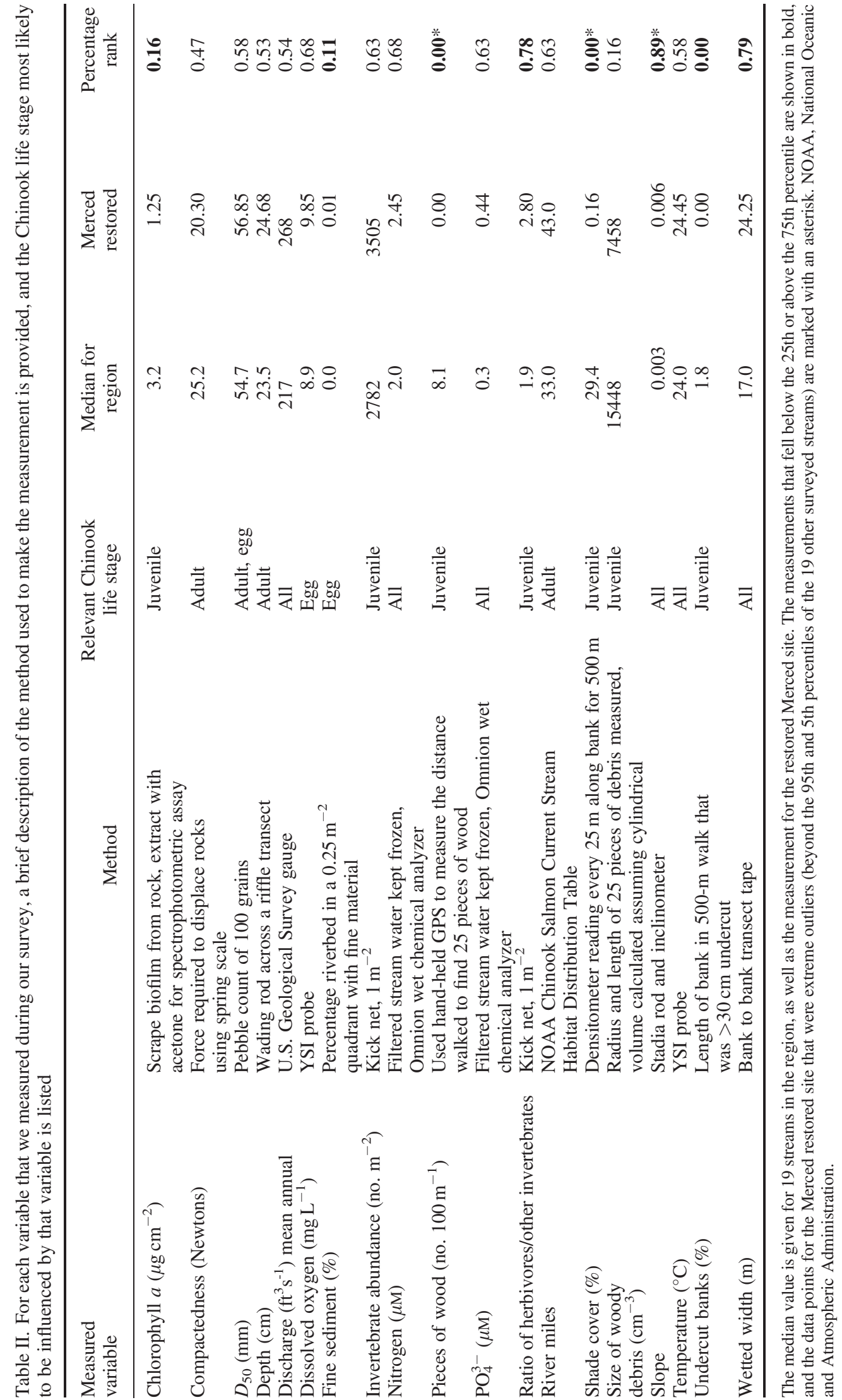


use conditions of the bed itself, like grain size and compactedness, to evaluate where to build redds (Groot and Margolis, 1991). To determine the grain-size distribution within each riffle, we sized 100 grains selected along transects across the wetted channel width using a Pebbleometer (Wildlife Supply Company, Yulee, FL, USA) and calculated the median grain size of the bed $\left(D_{50}\right)$. To assess the compactedness of the riverbed, we measured the force needed to shift a rock $\left(F_{\mathrm{c}}\right)$ using spring balance. This method was adopted from Sousa (1979) and Downes et al. (1997). A spring balance, either ranging to 1 or $10 \mathrm{~kg}$ depending on rock size, was attached to at least 100 rocks chosen haphazardly along the wetted channel width using a grappling hook. The grappling hooks were designed by bending a steel rod so that one end had two curved prongs that were attached to the upstream end of a randomly selected rock. The spring balance attached to the rod was then pulled downstream until the rock just began to move, and the mass was recorded. Spring balance readings were converted to units of force by Newton's law: $F_{\mathrm{c}}=$ mass $\times$ acceleration. Benthic fine sediment, a factor known to influence interstitial flow and thus egg survivorship, was measured at six randomly selected intervals along a transect spanning the channel wetted width. The number of intersection points that fell on fine sediment in a $0.5 \mathrm{~m}^{2}$ quadrant was visually counted through snorkelling.

Trophic status. To measure nutrient concentrations, which sometimes serve as an indicator of water quality, we passed water samples collected from the well-mixed midchannel through a $0.7-\mu \mathrm{m}$ filter (Whatman) into a $15-\mathrm{mL}$ falcon tube and capped the tube without air. The sample was immediately frozen, transported to the University of California-Santa Barbara (UCSB) using a portable freezer (Waeco CF-18) and analyzed for $\mathrm{NO}_{2}^{-}, \mathrm{NO}_{3}^{-}, \mathrm{NH}_{3}$ and $\mathrm{PO}_{4}^{3-}$ using an automated five-channel wet-chemical analyzer Omnion (Fia) system within 3 weeks by the UCSB Marine Science Institute Analytical Laboratory (http://www.msi.ucsb.edu/ services/analytical-lab). Chinook eggs are sensitive to dissolved oxygen $\left(\mathrm{mg} \mathrm{L}^{-1}\right)$ concentrations (Groot and Margolis, 1991), which we measured at midchannel using an YSI 85 probe (YSI Incorporated). Additionally, we quantified algal biomass from three randomly selected $50-\mathrm{mm}$ rocks at each riffle. Algal film was scraped from a circular area $\left(15.89 \mathrm{~cm}^{2}\right)$ on each rock, homogenized in $400 \mathrm{~mL}$ of stream water and filtered through a $0.7-\mu \mathrm{m}$ filter (Whatman). The filter was placed in $10 \mathrm{~mL}$ of $90 \%$ $\mathrm{EtOH}$, stored in a dark cooler and analyzed using spectrophotometry within 3 weeks for chlorophyll $a$ as a proxy for algal biomass.

Invertebrate composition, density and biomass. To quantify the amount and type of food available to juvenile salmon - the only life stage that actively feeds in-river-we measured invertebrate abundance, biomass and community structure at each riffle using a $1 \mathrm{~m}^{2}$ kick net $(500-\mu \mathrm{m}$ mesh). Invertebrates were processed in the laboratory using repeated counting of invertebrates in $X$ subsamples taken from our kick net sample until a minimum of 100 individuals were enumerated and identified using the guide presented by Merritt and Cummins (1996). After 100 individuals were enumerated, the $X$ th subsample was completed and the total abundance $A_{i}$ of each species $i$ per squared metre was calculated as $A_{i} * X$.

Woody debris, undercut banks and shade cover. To describe physical habitat structure that provides refuge from predators and low-flow resting spots for juvenile fish, we conducted a survey by walking along $500 \mathrm{~m}$ of riverbank in each stream that was sampled. During the survey, we measured the percentage of riverbank that was undercut, the average size of a piece of woody debris, the density of instream woody debris and the percentage of river bank that was shaded. We measured the percentage of the bank that was undercut by measuring the length of undercut sections within the 500-m walking distance. To measure the density of pieces of woody debris, we counted up to 25 pieces of wood (diameter $>6 \mathrm{~cm}$ ) and documented the distance we had walked until 25 pieces were counted using a hand-held GPS (Garmin, Olathe, KS, USA). We then calculated the number of pieces of wood $\mathrm{m}^{-1} * 100$ to report the number of pieces of wood $100 \mathrm{~m}^{-1}$. We also measured the length and width of each of these pieces of wood to calculate the average volume of a piece of wood (assuming a piece of wood was cylindrical in shape). We determined the extent of bank shading, a factor involved in predator refuge and temperature regulation, by recording percentage of shade cover over the river at a location approximately $1 \mathrm{~m}$ from the wetted bank edge using a hand-held spherical densitometer. Readings were collected every $25 \mathrm{~m}$ of the 500-m walk.

Statistical analyses for Merced restoration comparisons. To compare habitat conditions between our restored and reference sites in the Merced case study and other streams in the region, we used boxplots to examine whether the Merced restored and unrestored reaches lie within the 25th-75th percentiles of the region for the parameters sampled. Values for the number of pieces of wood $100 \mathrm{~m}^{-1}$ were natural log transformed, and percentage of undercut banks were arcsine square root transformed to reduce heteroscedasticity. We then calculated the percentage rank for key habitat features in the Merced to evaluate how the restoration site compared with the regional reference condition.

We also compared invertebrate community composition between the streams in which we sampled using distance- 
based non-metric multidimensional scaling. Here we aimed to establish whether there were differences in the types of invertebrates available for salmon to eat in different streams. To do this, we calculated distance matrices from relativized species densities derived from kick net samples using the Sørensen dissimilarity index (aka Bray-Curtis or Percent Dissimilarity, calculated as $1-2 W /[A+B]$ where $W$ is the sum of shared densities and $A$ and $B$ are the sums of densities in individual sample units [Sørensen, 1948]) using the software package PC-ORD (MjM Software Design, Gleneden Beach, OR, USA) (McCune and Mefford, 2006).

\section{Correlates of salmon density}

To determine if habitat conditions that we measured correlate with salmon population size in a river, we calculated salmon density in streams for which salmon population size estimates were available. To estimate fish density, we used what is referred to by CDFG as 'the GrandTab' file (available at www.calfish.org), which is a monitoring data set that is updated annually with estimates of Chinook population escapements for California's Central Valley. This monitoring programme provides estimates of Chinook population sizes for the San Joaquin and Sacramento Rivers and many of their tributaries.

One limitation of this data set is the inconsistency in the methods that have been used to estimate salmon populations (Table I). Not only have different methodologies been used among rivers, but also methodologies have been altered in different years for sampling the same river (Table I). There is, at present, no obvious way to calibrate the different forms of measurement. As a result, any use of this data set must assume that CDFG personnel have chosen a method that adequately, and appropriately, characterizes Chinook population size in each individual stream. Although this is an unverified assumption that could potentially make the reliability and comparability of the data tenuous (Williams, 2006), this is the only historical monitoring data set that exists for Chinook in California. As such, we chose to examine the existing data set despite its inconsistent methodology. But we discuss the potential limitations of our analyses later in the paper to ensure that readers are aware of the appropriate caveats. We are also careful to point out that all results that stem from analyses of this data set should be treated as hypotheses that remain to be confirmed by more reliable sources of data and mechanistic experiments.

After we compiled population estimates from the GrandTab file, we calculated fish density for a given stream. Previous studies have shown that larger rivers support larger populations of Chinook (see Healey, 1991, p. 317; Figure 4) and rivers in the Central Valley of California span a wide range of sizes. Therefore, we standardized across streams of different sizes by calculating the density of fish per mean annual discharge. Discharge measurements were chosen because they were easily accessible from USGS gauges across streams that we sampled and seemed to provide a more accurate measure of stream size than, for example, accessible watershed size or accessible river miles because most streams in California's Central Valley are dammed. The mean annual discharge of each stream was determined from continuous recordings taken at gauging stations at USGS sites (see Table $\mathrm{S} 1$ for gauge locations), and salmon density was calculated as the number of fish estimated to be in the population from the GrandTab file per river discharge. Although there are records of population size for some Central Valley streams back to the 1950 s, our survey was only conducted in 2008 . Thus, we focused our analysis on only the most recent years (2008 and 2007), for which our measurements were most representative. For rivers in the GrandTab file that report values for hatchery spawners (Battle Creek, Feather River, Merced River and Mokolumne River), we only used population estimates for in-river spawners.

Statistical analyses for correlates of salmon density. Principal components analysis (PCA) was used to establish which variables drive the environmental gradients in our data set. To aid in interpretation of PCA axes, we condensed information when possible (e.g. summed nitrogen and phosphorous to represent 'total nutrients') and removed variables from the data set that contained redundant information. For example, dissolved oxygen was highly correlated $\left(R^{2}>0.60\right)$ with temperature, and temperature appeared to be the more powerful explanatory variable for the various life stages of Chinook and so was removed from the PCA.

We used linear regression to test relationships between fall-run salmon density in 2008 and 2007, the 2 years closest to our survey period and the principal components calculated from habitat characteristics. Of the 20 streams in the Central Valley in which we sampled biological and physical habitat characteristics, our regression analysis was limited to only 13 streams because only these same streams had estimates of salmon population size for 2008 and 2007. Although salmon records do exist for several prior years, we were conservative and only ran this analysis for the most recent years when the variables that we measured are most likely to have the potential to directly relate to salmon densities. Salmon density values were natural $\log$ transformed to reduce heteroscedasticity. Again, we reiterate that this exercise is strictly correlative and was intended to identify key habitat characteristics that might provide information about the number of salmon that a river can support so that we could evaluate whether the case study in the Merced River has habitat characteristics that are present in other streams in the region that support relatively high densities of salmon. 


\section{RESULTS}

\section{Regional comparisons for the Merced}

Habitat features related to bulk flow and geomorphology in the restored Merced reach generally fell within the 25th-75th percentiles for the region (Table II). Water depth (Figure 1a) and discharge (Figure 1b), two factors that are potentially relevant for spawning locations and the construction of redds, were close to the average of the other 19 streams and fell within the 53rd and 54th percentage ranks, respectively. Temperature (Figure 1c), a variable relevant to all life stages of Chinook, was $24.5^{\circ} \mathrm{C}$ and fell in the 58th percentage rank compared with other streams in the region. As described in the Methods, this trend was for summer water temperatures. However, the strong correlation between spring versus summer water temperature ( $r=0.75, p=0.05)$ (Figure S1) suggests that this result would probably hold true for other seasons as well.

Mean rock size measured using pebble counts was $56.9 \mathrm{~mm}$ (Figure 1d), and compactedness, measured as the force required to displace rocks in the riffles using a spring scale, was 20.3 Newtons (Figure 1e), placing these factors in the 58th and 47th percentage ranks, respectively. Rock size and compactedness are two major components that determine redd location and quality during spawning. Percentage of fine material (Figure 1f), a feature important for egg survivorship, was low in the restored Merced and fell in the 11th percentage rank compared with the other 19 streams. This was probably because of the relatively recent addition of large particles during the gravel augmentation in the Merced River restoration effort.

a.

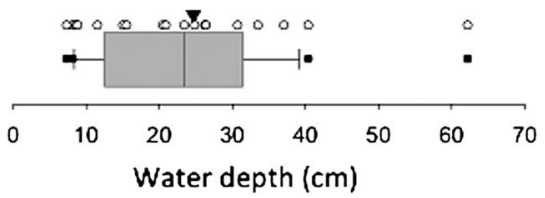

b.

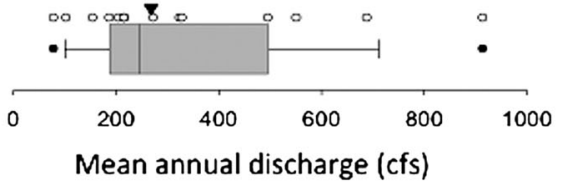

c.

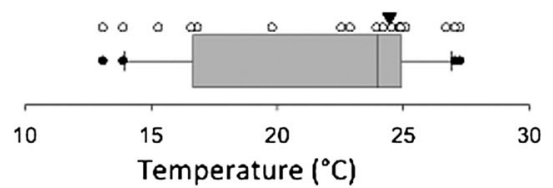

Factors that described the trophic status of streams that support salmon in the Central Valley showed that the Merced was generally similar to nearby streams (Table II). Total nitrogen and phosphorus (Figures $2 \mathrm{a}$ and $2 \mathrm{~b}$ ), both potential indicators of water quality, were higher than the median for the other 19 streams and fell in the 63rd and 68th percentage ranks, respectively. Dissolved oxygen concentrations that are important for egg survivorship were $9.8 \mathrm{mg}$ $\mathrm{L}^{-1}$ in the restored Merced and fell in the 68th percentage rank (Figure 2c). Chlorophyll $a$, the proxy for algal biomass and indicator of primary productivity, was low in the restored Merced and fell in the 16th percentage rank (Figure 2d).

Non-metric multidimensional scaling revealed that the invertebrate community, a food source for juvenile Chinook in the Merced, was similar to other rivers in the region (Figure 3a). In addition, the abundance of invertebrates (3505 individuals per squared metre) in the restored Merced fell in the 63rd percentage rank of the region (Figure 3b), suggesting that invertebrate abundance is relatively high in the restored site compared with nearby streams. In particular, the number of herbivores was higher (78th percentage rank) in the restored Merced than in other streams in the region (Figure 3c), which might help to explain the comparably low amount of algal biomass (see Figure 2d). These results suggest that the food web has shifted to be grazer dominated in the restored Merced but that the overall density and structure of the invertebrate community is similar to other streams in the region.

In contrast to the food supply, habitat structure in the restored Merced was notably absent (Table II). Following

d.

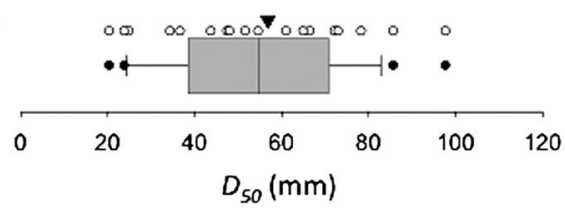

e.

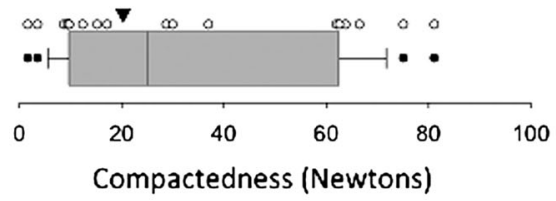

f.

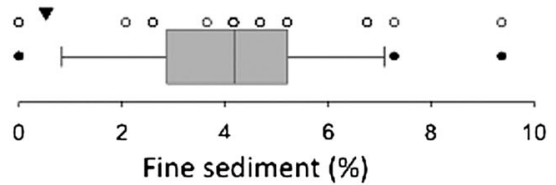

Figure 1. For each habitat characteristic that describes flow and geomorphology, the boxplot shows the distribution from all 19 streams from the region that were sampled. The raw data are shown as open circles above each boxplot, and the black triangle above the plot represents the Merced restored site. The shaded box extends from the 25th to 75th percentiles, the line crossing the box shows the median, the lines extending from the box show the 10th and 90th percentiles and filled black circles outside the lines show outliers. See Table II for measurement values and percentage ranks for the Merced restored site 


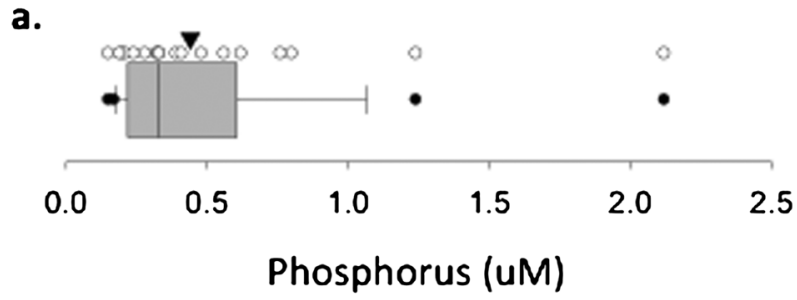

b.

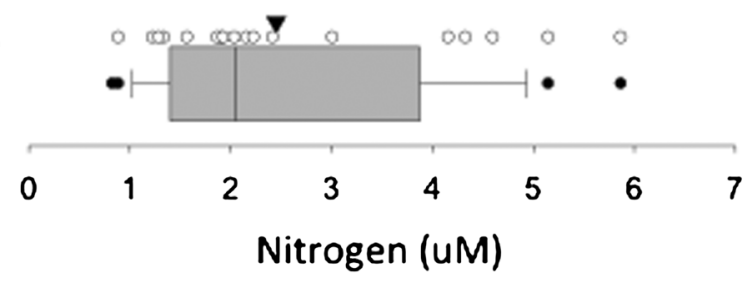

c.

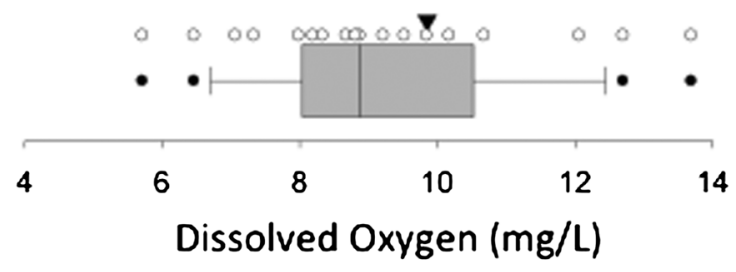

d.

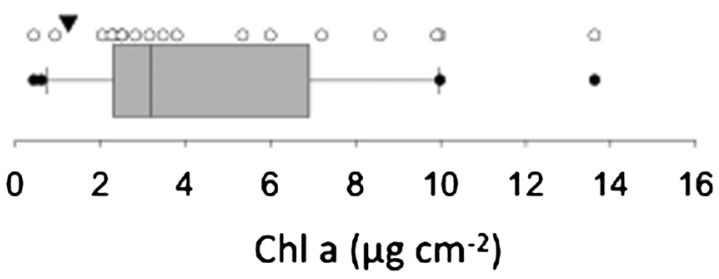

Figure 2. The boxplots illustrate the distribution of habitat characteristics from 19 streams in the region that describe trophic status of the system. The raw data are shown as open circles, and the black triangle above the plot represents the Merced restored site. Nutrient and dissolved oxygen concentrations in the Merced River fall within the 25th and 75th percentiles of the region. Algal biomass, as measured using chlorophyll $a$, is relatively low in the restored reach of the Merced

restoration, undercut banks (Figure 4a), the number of pieces of wood (Figure 4b), the average size of a piece of wood (Figure 4c) and shade cover (Figure 4d) were much lower in the restored Merced reach compared with other streams in the region. The restored Merced was in the 0th percentage rank for number of pieces of wood per $100 \mathrm{~m}$, undercut banks, and shade cover, and the single piece of woody debris that was found in the restored Merced was relatively small (16th percentage rank) compared with the pieces of woody debris found in the 19 other streams. These findings indicated that in-stream structure, including woody debris, undercut banks and shade cover - all of which provide refuge for juvenile fish from predators and high flow-are significantly lower, or completely missing, in the restored Merced.

\section{Correlates of salmon density}

Principal components analysis of biological and physical habitat characteristics in all of the streams sampled indicated that two axes explained $66 \%$ of all variation in the habitat characteristics (Figure 5a). Both of these axes represented interpretable sources of variation. The first axis represented a gradient in stream elevation. Streams on the first PC-axis ordinated from relatively small amounts of fine bed material, low nutrient concentrations and large $D_{50}$ that are representative of streams in the northern and mountainous part of the Central Valley, to higher amounts of fine material, high nutrients concentrations and small $D_{50}$ that are representative of streams in the low gradient, southern part of the Central Valley. The second PC-axis of the ordination appeared to represent in-stream structure and temperature. Streams ordinated along this axis tended to shift from relatively low amounts of undercut banks, fewer number of pieces of woody debris and higher temperature to relatively high amount of undercut banks, a higher density of woody debris and lower temperature. Thus, the two PC-axes represent gradients in habitat characteristics along ranges in geographic location and in-stream structure and temperature.

To determine if variation in the environmental gradients represented by $\mathrm{PC} 1$ and $\mathrm{PC} 2$ correlated with the size of Chinook populations, we used linear regression to compare the PCA axes with estimates of salmon density from recent years. Although we sampled 20 total streams, only 13 of the streams (including the Merced) had estimates in CDFG's GrandTab file and could be used for the analyses. We found that PCA axis 1, which represents geographic location, did not correlate with salmon density in 2008 (Figure 5b), the year when we completed our survey in California's Central Valley. In contrast, PCA axis 2, in-stream structure and temperature, showed a significant negative correlation with salmon density (Figure 5c). Salmon density-standardized by stream size - tended to be lower in streams that had relatively low amounts of undercut banks and woody debris as well as those streams with relatively high temperatures. These trends were consistent for salmon density in 2007, the year just before our sampling effort. In 2007, PCA axis 1 showed no relationship with salmon density $\left(R^{2}=0.08\right.$, $\left.p=0.79, F_{1,12}=0.08\right)$ and PCA axis 2 showed a significant negative relationship with salmon density $\left(R^{2}=0.42\right.$, $\left.p=0.02, F_{1,12}=8.0\right)$. These results indicate that population size was most associated with variation in water temperature and the amount of in-stream structure.

\section{DISCUSSION}

The bottlenecks that mediate restoration and recovery of salmon populations remain poorly understood despite the large amount of effort and funding being allocated to this 

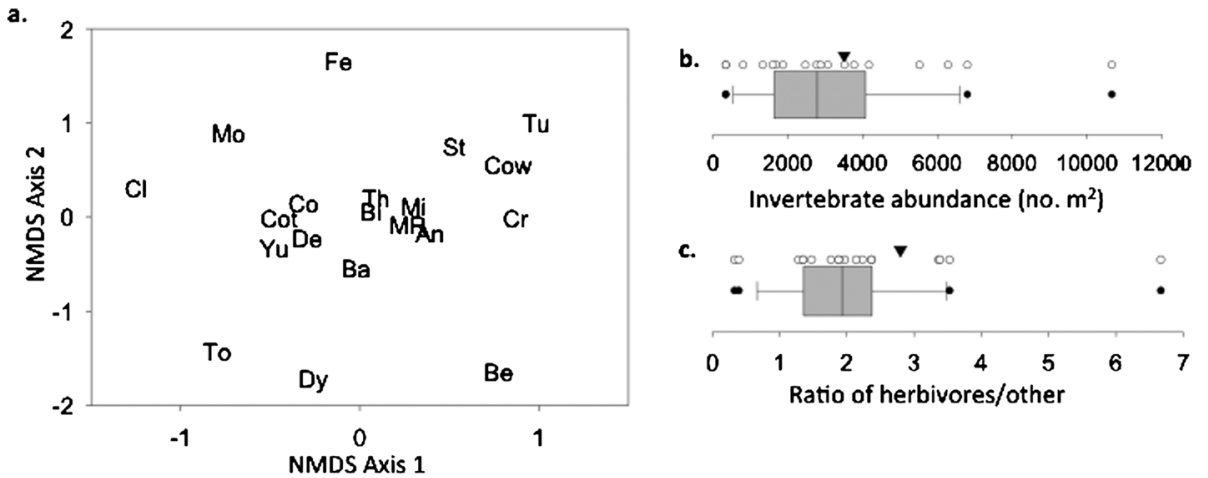

Figure 3. Non-metric multidimensional scaling (NMDS) ordination of invertebrate communities that serve as the food supply for juvenile salmon reveals that the type of food available in the Merced is similar to other rivers in the region that also support salmon (a). The Merced restored (MR) site falls at the centre of the plot, suggesting that it supports an invertebrate community similar to an average stream in the region. The boxplots illustrate that compared with other streams in the region, invertebrate abundance is similar (b) but the number of herbivores is relatively high (c). Open circles above the boxplots represent the raw data, and the black triangle above the boxplots represents the Merced restored site. Abbreviations of stream names in the NMDS are the first two letters of the stream name that is shown in Table I

a.

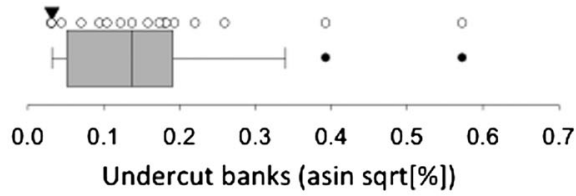

c.

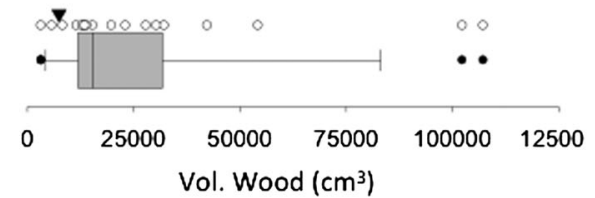

b.

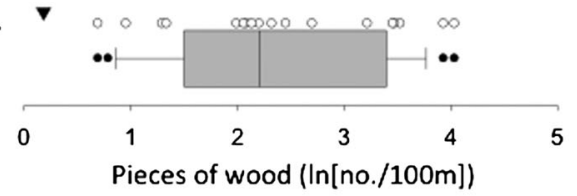

d.

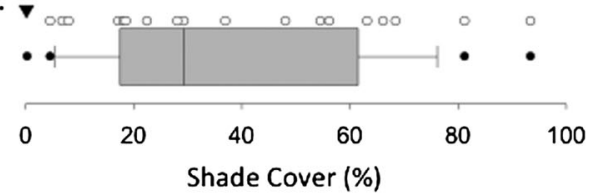

Figure 4. The boxplots illustrate the distributions of habitat characteristics from 19 streams in the region that describe habitat structure. The raw data are shown as open circles, and the black triangle above the boxplot represents the Merced restored site. Undercut banks (a), in-stream woody debris (b and c) and shade cover (d) are all virtually absent in the restored Merced River

economically, culturally and ecologically important fish. Here we have used a regional comparison to identify several habitat characteristics in a restoration site in California's Merced River that have potential to limit recovery of salmon populations in restored rivers. By comparing habitat characteristics with 19 other streams known to support salmon in the same geographic region, we found that flow, geomorphology, trophic status and food supply in the restored Merced River are all relatively similar to neighbouring streams. Thus, it seems unlikely that these features represent a bottleneck to salmon restoration. In contrast, we found that instream habitat structure is almost completely absent from the restored Merced River and that temperature in this restored site is higher than the typical of other salmon streams. Using a correlative analysis, we found that salmon density in California's Central Valley is higher in streams that have more in-stream habitat structure, like undercut banks and woody debris, and that are characterized by relatively low temperatures. Taken together, these findings lead us to hypothesize that the lack of undercut banks, woody debris and the higher temperature in the Merced River have potential to be key factors that limit the success of this restoration project.

The regional reference condition for the restored Merced River that we begin to establish in this study expands upon our previous attempts to evaluate what habitat characteristics are different in the restored Merced compared with an upstream reference location that is in close spatial proximity. In our prior spatial comparisons, we found that the restored Merced site had lower invertebrate abundance and biomass than the reference site. More importantly, this comparison showed a shift in the dominant prey item available for fish-from large benthic, filter-feeding caddisflies (Hydropsyche) in the unrestored reference site to comparably small and mobile mayflies (Baetis) 
a.

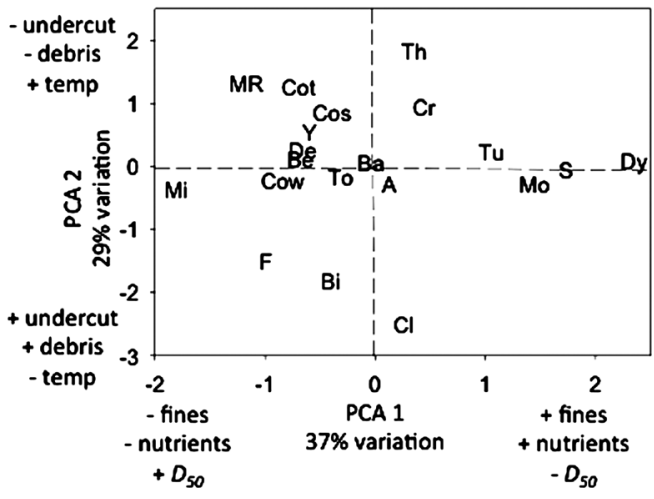

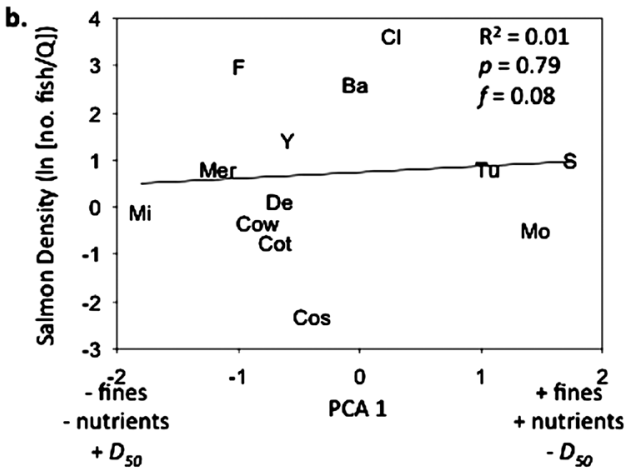

c.

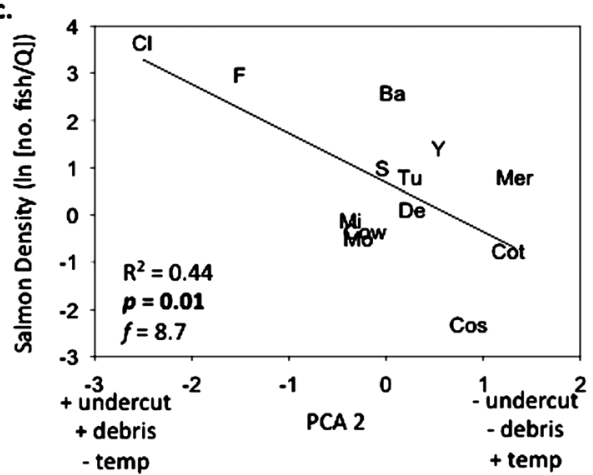

Figure 5. (a) Principal components analysis (PCA) shows that two axes explain the majority of variation in the data set. The first axis is an elevational gradient ranging from low fine material, low nutrients and high $D_{50}$ to high fine material, high nutrients and low $D_{50}$. The second axis of variation shifts from high undercut banks, high density of woody debris and low temperature to low undercut banks, low woody debris and high temperature. The restored Merced (MR) plots in the upper left-hand quadrant suggests that it has relatively high $D_{50}$, low nutrient concentrations and low fine material along PC1 and has few undercut banks, few pieces of woody debris and high temperature along PC2. Stream name abbreviations are either the first one or two letters of the stream name (see Table I), and plus (+) and minus (-) symbols represent high and low magnitude along each axis. (b) Correlation of PCA axis 1 with salmon density (estimated as number of fish per mean annual discharge) in 2008. PC1 shows no relationship with salmon density. (c) Correlation of PCA axis 2 with salmon density in 2008 . PC2 shows a significant negative relationship with salmon density

in the restored site (Albertson et al., 2010). Initially, this suggested to us that the quantity and quality of food might be a limitation in the restored Merced because juvenile fish that are unable to acquire enough food to reach a larger size generally suffer more mortality because of, for example, predation (Sogard, 1997), and bioenergetic constraints imposed by food availability, as well as current velocity and temperature, have been shown to be key determinants of young fish growth (Kitchell et al., 1977; Neilson and Geen, 1985; Nislow et al., 1999). However, the regional survey that we conducted shows that most streams in the region that support salmon populations have comparable amounts of invertebrates and are typically dominated by mayflies. In addition, we have recent evidence that suggests that juvenile salmon in the restored Merced River specialize their feeding on Baetis and that they have similar growth rates to populations upstream (Utz et al., in review). Thus, we suspect that the quantity and type of prey items available for juvenile feeding are not likely to limit the restoration effort.

In contrast to the food supply, we found that major habitat features that potentially provide low-flow refuge for juvenile fish growth and protection from predation are almost completely lacking in the restored Merced site. Undercut banks and woody debris are major habitat structures that provide low-flow refuges for juvenile salmonids (McMahon and Hartman, 1989; Rabeni and Jacobson, 1993; Roni and Quinn, 2001), and many studies have found that woody debris or artificial in-stream structures increase fish abundance (Robertson and Crook, 1999; Roni and Quinn, 2001; Neumann and Wildman, 2002; Finstad et al., 2007; Floyd et al., 2009). Reduction in shade cover, a common feature of restored river sites (Moerke and Lamberti, 2004), may also increase visibility to predators (McMahon and Hartman, 1989), as well as contribute to higher water temperatures that affect time to hatch, juvenile feeding and juvenile growth (Beacham and Murray, 1990). The potential impacts of temperature on Chinook are especially important to consider in the Merced, where the species is at its southernmost range limit (Moyle, 1976). It is possible that these habitat characteristics that are missing from the restored Merced are evolving very slowly because recruitment of riparian vegetation is often on the scale of $1-5$ years and 
depends heavily on flooding regime and seed bank dynamics, characteristics that have been altered in most rivers like the Merced that are flow regulated (Stromberg, 2001; Jensen et al., 2008). But even 8 years postchannel reconfiguration, there is still no sign that riparian vegetation that would provide woody debris, bank structure or shade cover to the Merced restoration site is developing.

Not only did our survey show that undercut banks, woody debris and shade cover are missing from the restored Merced but also we found that these same factors correlated most strongly to salmon density across streams throughout the region. The strength and consistency of these correlations surprised us considering the inconsistency of methods that have been used to determine population sizes in California's Central Valley (Williams, 2006; Johnson et al., 2007). Because of these inconsistencies in methodology, the correlations should not be viewed as anything more than hypotheses that remain to be tested. Even so, if the key habitat features that are missing from the Merced restored site are influencing juvenile survivorship, then it is a reasonable possibility that salmon density will be impacted. Previous studies have shown that juvenile size at smolting shows a strong positive correlation with adult survival (Bilton et al., 1982; Ward and Slaney, 1988; Lundqvist et al., 1994), and survival of first-year salmon has been shown to positively influence population stock sizes (Emlen, 1995). In California's Central Valley, recent evidence suggests that juvenile survivorship is extremely low and that allocating water to improve juvenile survivorship might enhance population recovery (Brown et al., 2009).

In summary, we have used a case study from a restored site in California's Merced River to identify select habitat features that have potential to limit the success of efforts to restore Chinook salmon. We found that many features of this system that influence spawning habitat or egg survival are in good shape. This is not surprising given that increased spawning habitat was the intended goal of this restoration effort, and other studies have verified that restoration projects like that in the Merced create suitable habitat for spawning adult salmon (Merz and Setka, 2004; Harrison et al., 2011). However, it appears that many habitat features that are required for the successful rearing of juvenile salmon have been neglected in the restoration design, and these features pose a potential bottleneck to this portion of the salmon life cycle. Studies like ours, which seek to indentify the potential bottlenecks to restoration, are especially important considering that salmon populations are continuing to decline in California despite the substantial amount of funding that has been allocated to restoration efforts. To improve our current approach, restoration efforts must include a suite of biological and physical habitat characteristics that are required to support all stages of the Chinook salmon life cycle.

\section{ACKNOWLEDGEMENTS}

We thank T. Dunne, I. Carroll, B. Kendall, K. Kulacki, H. Lenihan and R. Nisbet for advice on study design and J. Byrnes, C. Kurle and D. Viola for advice on statistical analyses. Many people confirmed which methods were used to estimate salmon population sizes in the GrandTab file, including J. Anderson, C. Harvey Arrison, D. Blakeman, J. Guignard, K. Hartwigsen, M. Healey, T. Heyne, D. Killam, D. Massa, T. McReynolds and M. Workman. C. Robinson and L. Robinson generously provided access to the Merced River restoration site. This work was supported by the Calfed Bay-Delta Authority and a Worster Grant from the Ecology, Evolution, and Marine Biology Department at UCSB to L. Albertson and L. Koenig.

\section{REFERENCES}

Albertson LK, Cardinale BJ, Zeug SC, Harrison LR, Lenihan HS, Wydzga MA. 2010. Impacts of channel reconstruction on invertebrate assemblages in a restored river. Restoration Ecology 19: online early.

Barbour MT, Gerritsen J, Snyder BD, Stribling JB. 1999. Rapid bioassessment protocols for use in streams and wadeable rivers: periphyton, benthic macroinvertebrates and fish, Second Edition. EPA 841-B-99-002. U.S. Environmental Protection Agency; Office of Water; Washington, D.C.

Beacham TD, Murray CB. 1990. Temperature, egg size, and development of embryos and alevins of five species of Pacific salmon: a comparative analysis. Transactions of the American Fisheries Society 119: 927-945.

Bernhardt ES, Palmer MA, Allan JD, Alexander G, Barnas K, Brooks S, Carr J, Clayton S, Dahm C, Follstad-Shah J, Galat D, Gloss S, Goodwin P, Hart D, Hassett B, Jenkinson R, Katz S, Kondolf GM, Lake PS, Lave R, Meyer JL, O'Donnell TK, Pagano L, Powell B, Sudduth E. 2005. Ecology: synthesizing U.S. river restoration efforts. Science 308: 636-637.

Bilton H, Alderdice D, Schnute J. 1982. Influence of time and size at release of juvenile Coho salmon (Oncorhynchus kisutch) on returns at maturity. Canadian Journal of Fisheries and Aquatic Sciences 39: 426-447.

Brinson MM, Rheinhardt R. 1996. The role of reference wetlands in functional assessment and mitigation. Ecological Applications 6: 69-76.

Brown L, Kimmerer W, Brown R. 2009. Managing water to protect fish: a review of California's Environmental Water Account, 2001-2005. Environmental Management 43: 357-368.

California Department of Water Resources. 2001. The Merced River salmon habitat enhancement project: Robinson reach; Phase III. San Joaquin District, Fresno, CA. 159 p. Available at http://www.water.ca.gov/pubs/ environment/restoration/merced_river_salmon_habitat_enhancement project_phase_iii_-_robinson_reach_engineering_report/mrshep3a.pdf Accessed on September 2007.

Chapman DW. 1988. Critical review of variables used to define effects of fines in redds of large salmonids. Transactions of the American Fisheries Society 117: 1-21.

Cottingham, KL, Lennon JT, Brown BL. 2005. Knowing when to draw the line: designing more informative ecological experiments. Frontiers in Ecology and the Environment 3: 145-152.

Downes BJ, Glaister A, Lake PS. 1997. Spatial variation in the force required to initiate rock movement in 4 upland streams: implications for estimating disturbance frequencies. Journal of the North American Benthological Society 16: 203-220.

Emlen JM. 1995. Population viability of the Snake River Chinook salmon (Oncorhynchus tshawytscha). Canadian Journal of Fisheries and Aquatic Sciences 52: 1442-1448. 
Finstad A, Einum S, Forseth T, Ugedal O. 2007. Shelter availability affects behaviour, size-dependent and mean growth of juvenile Atlantic salmon. Freshwater Biology 52: 1710-1718.

Floyd T, Macinnis C, Taylor B. 2009. Effects of artificial woody structures on Atlantic salmon habitat and populations in a Nova Scotia stream. River Research and Applications 25: 272-282.

Groot G, Margolis L (eds). 1991. Pacific Salmon: Life Histories. University of British Columbia Press: Vancouver, British Columbia.

Healey MC. 1991. "Life History of chinook salmon (Oncorhynchus tshawytscha)". In Groot C, Margolis L. (ed). Pacific Salmon Life Histories. UBC Press: Vancouver, British Columbia.

Harrison LR, Legleiter CJ, Wydzga MA, Dunne T. 2011. Channel dynamics and habitat development in a meandering, gravel bed river. Water Resources Research 47: online early.

Hicks BJ, Hall JD, Bisson PA, Sedell JR. 1991. Responses of salmonids to habitat changes. In Influences of Forest and Rangeland Management on Salmonid Habitat: American Fisheries Society Special Publication 19, Meehan WR (ed). American Fisheries Society: Bethesda, MD; 483-518.

Hughes RM, Peck DV. 2008. Acquiring data for large aquatic resource surveys: the art of compromise among science, logistics, and reality. Journal of the North American Benthological Society 27: 837-859.

Jensen A, Walker K, Paton D. 2008. The role of seedbanks in restoration of floodplain woodlands. River Research and Applications 24: 632-649.

Johnson DH, Shrier BM, O'Neal JS, Knutzen JA, Augerot X, O'Neil TA, Pearsons TN. 2007. Salmonid Field Protocols Handbook: Techniques for Assessing Status and Trends in Salmon and Trout Populations. American Fisheries Society: Bethesda, MD.

Jungwirth M, Muhar S, Schmutz S. 2002. Re-establishing and assessing ecological integrity in riverine landscapes. Freshwater Biology 47: 867-887.

Kitchell J, Stewart D, Weininger D. 1977. Applications of a bioenergetics model to yellow perch (Perca flavescens) and walleye (Stizostedion vitreum vitreum). Journal of the Fisheries Research Board of Canada 34: 1922-1935.

Kondolf GM, Mathews WVG. 1993. Management of coarse sediment in regulated rivers in California. Report Number 80. University of California Water Resources Center: Riverside.

Kondolf GM, Anderson S, Lave R, Pagano L, Merenlender A, Bernhardt ES. 2007. Two decades of river restoration in California: what can we learn? Restoration Ecology 15: 516-523.

Legleiter CJ, Harrison LR, Dunne T. 2011. Effect of point bar development on the local force balance governing flow in a simple, meandering gravel-bed river. Journal of Geophysical Research Earth Surface 116(F01005).

Liermann M, Roni P. 2008. More sites or more years? Optimal study design for monitoring fish response to watershed restoration. North American Journal of Fisheries Management 28: 935-943.

Low A. 2007. Existing Program Summary: Central Valley Salmon and Steelhead Monitoring Programs. The Department of Fish and Game: Sacramento, CA.

Lundqvist H, McKinnell S, Fangstam H, Berglund I. 1994. The effect of time, size and sex on recapture rates and yield after river releases of Salmo salar smolts. Aquaculture 121: 245-257.

McCune B, Mefford MJ. 2006. PC-ORD v5. Multivariate analysis of ecological data.

McMahon TE, Hartman GF. 1989. Influence of Cover complexity and current velocity on winter habitat use by juvenile Coho salmon (Oncorhynchus kisutch). Canadian Journal of Fisheries and Aquatic Science 46: 1551-1557.

Merritt KW, Cummins RW (eds). 1996. An Introduction to the Aquatic Insects of North America. Kendall/Hunt Publishing Company: Dubuque, IA.
Merz JE, Setka JD. 2004. Evaluation of a spawning habitat enhancement site for Chinook salmon in a regulated California river. North American Journal of Fisheries Management 24: 397-407.

Moerke AH, Lamberti GA. 2004. Restoring stream ecosystems: lessons from a midwestern state. Restoration Ecology 12: 327-334.

Moyle PB. 1976. Inland Fishes of California. University of California Press: Berkeley, CA.

Moyle PB. 1994. The decline of anadromous fishes in California. Conservation Biology 8: 869-870.

Neilson JD, Geen GH. 1985. Effects of feeding regimes and diel temperature cycles on otolith increment formation in juvenile Chinook salmon, Oncorhynchus tshawytscha. Fisheries Bulletin 83: 91-101.

Neumann R, Wildman T. 2002. Relationships between trout habitat use and woody debris in two southern New England streams. Ecology of Freshwater Fish 11: 240-250.

Nislow KH, Folt CL, Parrish DL. 1999. Favorable foraging locations for young Atlantic salmon: application to habitat and population restoration. Ecological Applications 9: 1085-1099.

Palmer M 2009. Reforming watershed restoration: science in need of application and applications in need of science. Estuaries and Coasts 32: $1-17$.

PFMC (Pacific Fisheries Management Council). 2008. Record low salmon fisheries adopted. Available at www.pcouncil.org/newsreleases/PFMC_FINAL_ PressRel.pdf [accessed on 1 January 2009].

Poff N, Ward J. 1990. Physical habitat template of lotic systems: recovery in the context of historical pattern of spatiotemporal heterogeneity. Environmental Management 14: 629-645.

Rabeni CF, Jacobson RB. 1993. The importance of fluvial hydraulics to fish-habitat restoration in low-gradient alluvial streams. Freshwater Biology 29: 211-220.

Robertson AI, Crook DA. 1999. Relationships between riverine fish and woody debris: implications for lowland rivers. Marine and Freshwater Resources 50: 941-953.

Romanov AM, Hardy J, Zeug SC, Cardinale BJ. in revision. Response of Sacramento pikeminnow (Ptychocheilus grandis) to a large-scale stream channel restoration in California. Fisheries Management and Ecology. Soutwestern Naturalist.

Roni, R 2005. Monitoring Stream and Waterhshed Restoration. American Fisheries Society, Bethesda, MD.

Roni P, Quinn TP. 2001. Density and size of juvenile salmonids in response to placement of large woody debris in western Oregon and Washington streams. Canadian Journal of Fisheries and Aquatic Science 58: 282-292.

Sogard S 1997. Size-selective mortality in the juvenile stage of teleost fishes: a review. Bulletin of Marine Science 60: 1129-1157.

Sørensen TJ. 1948. A method of establishing groups of equal amplitude in plant sociology based on similarity of species content and its application to analysis of the vegetation of the Danish Commons. Biologiske Skrifter 5: $1-34$.

Sousa WP. 1979. Disturbance in marine intertidal boulder fields: the nonequilibrium maintenance of species diversity. Ecology 60: 1225-1239.

Stewart-Oaten A, Murdoch WW, Parker KR. 1986. Environmental impact assessment: "pseudoreplication" in time? Ecology 67: 929-940.

Stromberg J 2001. Restoration of riparian vegetation in the south-western United States: importance of flow regimes and fluvial dynamism. Journal of Arid Environments 49: 17-34.

Trush WJ, McBain SM, Leopold LB. 2000. Attributes of an alluvial river and their relation to water policy and management. Proceedings of the National Academy of Sciences of the United States of America 97: 11858-11863.

Utz RM, Zeug SC, Cardinale BJ, in review. Juvenile Chinook salmon (Oncorhynchus tshawytscha) growth and diet in riverine habitat engineered to improve conditions for adult spawning. Fisheries Management \& Ecology. 
Ward B, Slaney P. 1988. Life-history and smolt-to-adult survival of Keogh River steelhead trout (Salmo gairdneri) and the relationship to smolt size. Canadian Journal of Fisheries and Aquatic Sciences 45: 1110-1122.

Williams JG. 2006. Central valley salmon: a perspective on Chinook and steelhead in the Central Valley of California. San Francisco Estuary and Watershed Science 4: Article 2.
Yoshiyama RM, Gerstung ER, Fisher FW, Moyle PB. 2001. Historical and present distribution of Chinook salmon in the central valley drainage of California. Fisheries Bulletin 179: 71-176.

Ziemer RR. 1997. Temporal and spatial scales. In Williams JE, Wood CA, Dombeck MP (eds). Watershed Restoration: Principles and Practices. American Fisheries Society: Bethesda, MD; 80-95. 